\title{
Carcinoembryonic Antigen-Related Cell Adhesion Molecule 6
}

National Cancer Institute

\section{Source}

National Cancer Institute. Carcinoembryonic Antigen-Related Cell Adhesion Molecule 6. NCI Thesaurus. Code C107471.

Carcinoembryonic antigen-related cell adhesion molecule 6 (344 aa, $37 \mathrm{kDa}$ ) is encoded by the human CEACAM6 gene. This plays a probable role in both cell-cell signaling and cell adhesion. 